\title{
Reducing Water Vapor Permeability of Poly(lactic acid) Film and Bottle through Layer-by-Layer Deposition of Green-Processed Cellulose Nanocrystals and Chitosan
}

\author{
Katalin Halász, Yanin Hosakun, and Levente Csóka \\ Institute of Wood Based Products and Technologies, University of West Hungary, Sopron 9400, Hungary \\ Correspondence should be addressed to Levente Csóka; levente.csoka@skk.nyme.hu
}

Received 30 December 2014; Revised 8 March 2015; Accepted 25 March 2015

Academic Editor: Huining Xiao

Copyright (C) 2015 Katalin Halász et al. This is an open access article distributed under the Creative Commons Attribution License, which permits unrestricted use, distribution, and reproduction in any medium, provided the original work is properly cited.

Layer-by-layer electrostatic self-assembly technique was applied to improve the barrier properties of poly(lactic acid) (PLA) films and bottles. The LbL process was carried out by the alternate adsorption of chitosan $(\mathrm{CH})$ (polycation) and cellulose nanocrystals (CNC) produced via ultrasonic treatment. Four bilayers (on each side) of chitosan and cellulose nanocrystals caused 29 and $26 \%$ improvement in barrier properties in case of films and bottles, respectively. According to the results the LbL process with $\mathrm{CH}$ and CNC offered a transparent "green" barrier coating on PLA substrates.

\section{Introduction}

Poly(lactic acid) (PLA) is a biodegradable and compostable bioplastic, which can be used widely in the packaging industry due to its heat formability, injection, and blow moldability and due to its properties like excellent transparency, good oil, chemical and UV resistance, and satisfying mechanical and thermal properties. However, PLA is not suitable for liquid products where long shelf-life is demanded, for products which are sensitive to moisture or for carbonated beverages because of the high water vapor and gas permeability. To make PLA an appropriate packaging material for these kinds of products, improvement of its barrier properties is required.

Layer-by-layer coating technique, which is based on the self-assembly of polyelectrolytes and/or nanoparticles on substrates, has many advantages compared to other coating methods like spin coating, thermal deposition, or solution casting. According to Jang et al. [1] LbL self-assembled nanostructured coatings provide both transparency and flexibility, making them good alternatives in packaging applications. The process is inexpensive, simple, and quick and it can be carried out in water media excluding using harmful and toxic solvents. It offers ultrathin film creation with desired composition and properties on several kinds of substrates with different sizes, irregular shapes, and 3D forms. A wide variety of materials can be used to perform the LbL deposition including inorganic or organic polycations, polyanions, and nanoparticles which have surface charges when solved or dispersed in water (or other processing media). LbL self-assembly is based on electrostatic attractions between the oppositely charged constituents, although hydrogen-bonding, van der Waals forces or charge-transfer interactions can also play a role in the thickness or in the stability of the self-assembled layers. With LbL deposition, ultrathin mono-, bi-, or multilayer coating can be achieved with more than $1 \mathrm{~nm}$ precision. The properties of the films can be fine-tuned by varying the process parameters like components, concentration, $\mathrm{pH}$, ionic strength, and immersion time [2-6].

Recent studies showed that montmorillonite (MMT) and poly(ethylene-imine) (PEI) bilayers can enhance the oxygen barrier properties of PET films [7, 8] and water vapor barrier properties of cellulose films [6] as well. Findenig et al. [6] also examined 2-hydroxy-3-trimethylammonium propyl chloride (HPMA) starch, PDDA, and chitosan as polyelectrolytes. It was concluded that it is possible to improve the water vapor barrier properties with hydrophilic components; they observed that PEI and HPMA starch are the most suitable for the preparation of transparent barrier coatings. Although chitosan was not as effective as PEI or starch in case of reducing the water vapor transmission rate with MMT, it was suitable 


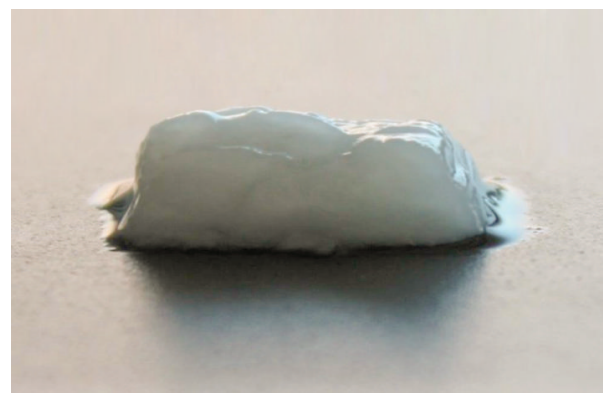

FIGURE 1: Nanocellulose gel formed after sonication and solvent exchange.

for reducing oxygen transmission not only in case of PET but also in case of PLA reported by Svagan et al. [9] and Laufer et al. [10]. Svagan et al. [9] observed 95\% reduction in oxygen permeability and $20 \%$ reduction in water vapor transmission after deposition of 70 MMT-CH bilayers. Laufer et al. [10] created 10 quadrat layers (CH-PAA-CH-MMT) on PLA and PET films which could significantly reduce the oxygen permeability of both packaging materials. Laufer et al. [11] also reported a high barrier effect with high transparency of 10 trilayers of CH-MMT-CR (carrageenan) and 10 quadrat layers of $\mathrm{CH}-\mathrm{CR}-\mathrm{CH}-\mathrm{MMT}$.

According to the literature, the most extensively studied LbL barrier coating nanomaterial is the layered silicate montmorillonite [6-10]; however, other materials might be suitable for barrier improvers as well. Hagen et al. [12] recently showed that polyelectrolytes can be enough to reduce the oxygen transmission rate, and eight bilayers of PEI-PAA (poly(acrylic acid)) deposited onto PET film could lead to undetectable oxygen transmission rate. Hirvikorpi et al. [13] created ultrathin multilayer on PLA film substrate from sodium alginate, chitosan (deposited by LbL method), and $\mathrm{Al}_{2} \mathrm{O}_{3}$ nanoparticles (deposited by atomic layer deposition). In contrast to Hagen et al. [12], they observed that multilayer containing only polyelectrolytes enhanced the WVTR while coating with an extra $\mathrm{Al}_{2} \mathrm{O}_{3}$ layer the WVTR became significant (47\%) lower.

In this study, chitosan and "green-" processed cellulose nanocrystal were deposited on poly(lactic acid) film and bottle with the aim of reducing water vapor transmission rate.

\section{Materials and Methods}

Poly(lactic acid) film was extruded with the thickness of 30 microns using Esun AI1031 transparent PLA granulates (Shenzhen Bright China Industrial Co.). PLA bottles with wall thickness of 680 microns and inner volume of $150 \mathrm{~mL}$ were kindly provided by Biopackpro Ltd. Microcrystalline cellulose (particle size $<20 \mu \mathrm{m}$ ) and chitosan were obtained from Sigma Aldrich.

To create cellulose nanocrystal colloid ultrasonic treatment of the MMC in distilled water was applied. The concentration of the suspension was set to $1.0 \mathrm{wt} \%$ and the sonication was carried out using ultrasonic horn with $20 \mathrm{kHz}$ $\left(35 \mathrm{~W} / \mathrm{cm}^{2}\right)$ for $80 \mathrm{~min}$. After sonication of the sediment, larger cellulose particles were removed, dried, and weighted in order to define the final concentration of the CNC colloid which was given to be $0.7 \mathrm{wt} \%$. To prove that the treated cellulose is nanosized, solvent exchange was carried out with acetone. The resulting material which was a nanocellulose gel can be seen in Figure 1. Although the appearance of the cellulose nanocrystals has not been examined in this research, according to our previous study, we can assume that the ultrasonically produced, above described, cellulose nanocrystal might have spherical form rather than whisker, which can be obtained through the acidic hydrolysis [14, 15].

The positively charged chitosan polyelectrolyte solution was prepared by dissolving $\mathrm{CH}(0.1 \mathrm{wt} \%)$ in $0.1 \mathrm{M}$ lactic acid. To achieve less expanded polymer coil, thus obtaining thicker chitosan layers in the multilayer, the $\mathrm{pH}$ was adjusted to 6 by adding $1 \mathrm{M} \mathrm{NaOH}$ to the polyelectrolyte solution.

Layer-by-layer method was carried out as follows: the PLA films and bottles were immersed into the positively charged chitosan solution; after rinsing the packaging objects with distilled water they were immersed into the negatively charged CNC colloid until reaching the adsorption equilibrium. After alternate adsorption of $\mathrm{CH}$ and $\mathrm{CNC}, 4$ and 8 bilayers were built up on each side of the substrates.

\section{Characterization}

To monitor the formation of the deposited layers, to make gravimetric and thickness analysis Quartz Crystal Microbalance (QCM) measurement was carried out. Since the deposition of mass onto the quartz crystal surface causes a measurable frequency shift, the adsorbed mass and the layer thickness were calculated with the Sauerbrey equation. To prevent measuring failure, which comes from the density and pressure of the liquids after the immersions, before the measurement, drying was applied. The surface modifying effects of the resulted coatings on the PLA substrates were tested by contact angle measurement with PGX goniometer. The microstructure of the surface was characterized by scanning electron microscopy (SEM) (Hitachi S-3400N), where the acceleration voltage was $20 \mathrm{kV}$. UV-VIS spectrophotometry was used to evaluate the transmittance of the coated PLA films in the visible range $(400-800 \mathrm{~nm})$. Transmittance of the films was measured in three different sites. Water vapor transmission rate tests were done in a climate chamber at $23^{\circ} \mathrm{C}$ and $85 \mathrm{RH} \%$ for 7 days in the case of both films and bottles. During the tests, three samples of each of modified PLA films and bottles and control samples were tested. 


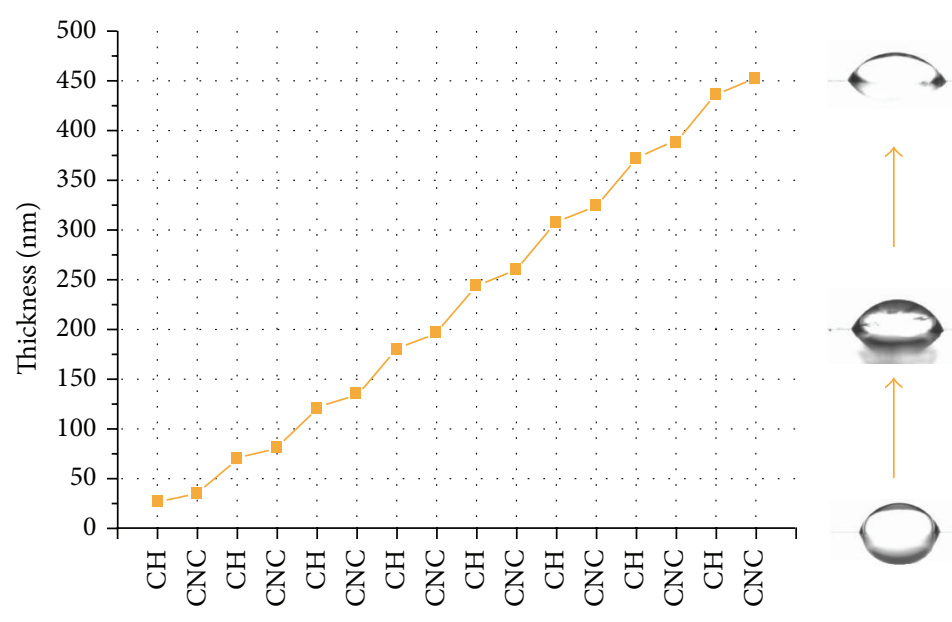

FIGURE 2: Thickness of the deposited $\mathrm{CH}$ and CNC layers and surface energy change in a function of deposition cycles.

\section{Results and Discussions}

Figure 2 shows the results of the Quartz Crystal Microbalance and contact angle, surface energy $\left(\gamma_{s}^{d}\right)$ measurements. According to the QCM CH and CNC required approximately 2 and 4 minutes, respectively, to achieve the adsorption equilibrium. The layer growth was linear and each layer contained around 2-2.4 $\mu \mathrm{g} / \mathrm{cm}^{2}$ chitosan and cellulose. As QCM showed the thickness of the deposited chitosan layer was around $50 \mathrm{~nm}$ and the thickness of the CNC layer was approximately $20 \mathrm{~nm}$ which indicates also that the maximal size of the ultrasonically produced CNC is around $20 \mathrm{~nm}$ if we assume that a monolayer was formed on the substrate. Thickness of the LbL deposited multilayer film (consisting of 4 bilayers of $\mathrm{CH}$ and $\mathrm{CNC}$ ) formed on the quartz crystal surface was $196 \mathrm{~nm}$. The 4 bilayers deposited on PLA films caused surface energy shift from $39.5 \mathrm{mN} / \mathrm{m}$ to $41.8 \mathrm{mN} / \mathrm{m}$. In case of 8 bilayers, the thickness of the multilayer increased to $452 \mathrm{~nm}$ and the surface energy of the PLA increased from 39.5 to $44.3 \mathrm{mN} / \mathrm{m}$. During the LbL process, uniform layer deposition and reproducible film growth were achieved.

According to the SEM images (Figure 3) of the neat and coated PLA films, either under 130x or under 1600x magnification, well-packed, dense multilayers without aggregation of the CNC particles were deposited onto the PLA substrate. Before the scanning electron microscopy the films were bent, but as the SEM images show it had no visible effect on the coatings, no microcracking could be observed.

UV-VIS spectrophotometry revealed that, in the range of visible radiation, the transmittance of the coated PLA films slightly, but not remarkably, decreased. The neat PLA film has $89 \%(\sigma=3)$ transmittance and the coated PLA films, $4 *$ $(\mathrm{CH}-\mathrm{CNC})$ and $8 *(\mathrm{CH}-\mathrm{CNC})$, have $85(\sigma=2)$ and $82 \%(\sigma=$ 3 ), respectively. Figure 4 shows the transparency of the modified and unmodified samples. The coating caused only slight little scattering in the visible range so it can be concluded that the deposited films are thin, uniform, and homogenous (in accordance with the observations during scanning electron microscopy). The negligible decrease in transmittance shows also that the cellulose particles, formed during the ultrasonic treatment, are in the nanometer range.
According to the water vapor transmission rate tests, whose results are presented in Figure 5, in case of $4 *$ (CH-CNC) films 29\% less water vapor was permeated through the material compared to in case of the neat PLA films. However, the $8 *(\mathrm{CH}-\mathrm{CNC})$ films showed almost as high WVTR as the neat PLA. Although chitosan is a hydrophobic polymer the high water content of the environment might have a plasticizing effect on the chitosan as Svagan et al. [9] reported. Analogue to Svagan et al.s [9] observation, in case of $\mathrm{CH}$ and MMT, the presence of water could interfere with the molecular interaction between $\mathrm{CH}$ and $\mathrm{CNC}$ with increased mobility of $\mathrm{CH}$ (which increases free volume) in the interfacial areas, which could modify the structure of the coating thus reducing the barrier effect. In case of bottles, the same phenomenon was observed. Presumably at the outmost layer there is an extensive interpenetration of deposited layers. Such phenomenon was observed by Fu et al. (2005) [16]. Many chitosan chains from the underlying layer can penetrate into the surface of the outmost CNC layer. The penetration perhaps can enhance the plasticizing effect of moisture on chitosan and hence reduce the water vapor barrier property. Figure 6 shows the assumed water vapor transmission rate reducing mechanism of the $\mathrm{CH}-\mathrm{CNC}$ nanocoating. The barrier effect presumably can be attributed to the cellulose nanocrystals rather than to the chitosan. It has been shown that cellulose nanocrystals can significantly decrease the WVTR if it is used as reinforcement even in small ratios in PLA matrix $[17,18]$. Though the barrier effect of the polymer is might be not as negligible either it rather acts as a binder and the nanoparticles as nanoshield. If the nanoparticles are tightly packed and impermeable to water vapor (which can occur if the cellulose is highly crystalline) these can cause an extreme tortuous path to water vapor molecules, thus reducing the rate of their passage through the material.

\section{Conclusions}

Multilayer built up with chitosan and ultrasonically greenproduced cellulose nanocrystals form a dense, well-packed, 

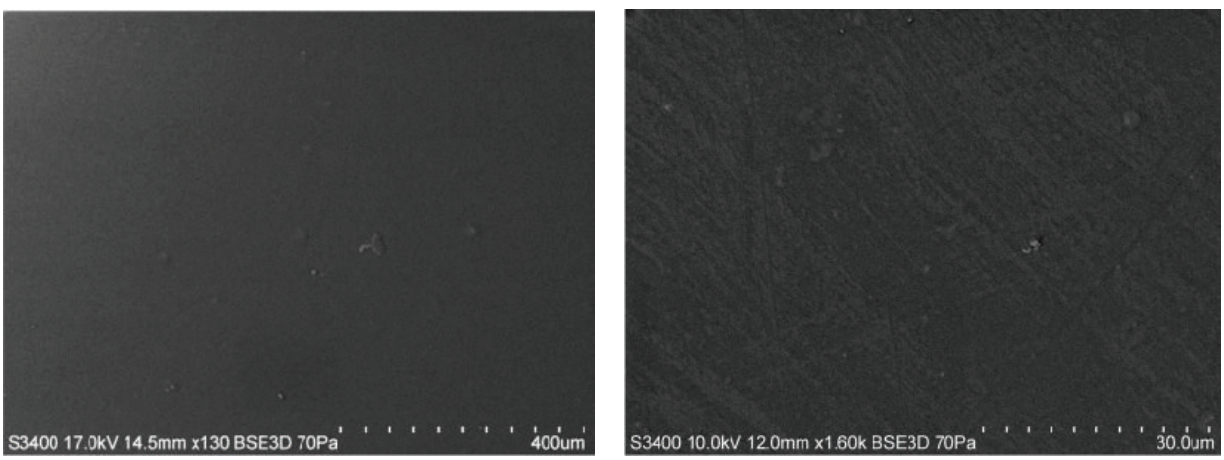

Coated PLA film $-4 *(\mathrm{CH}-\mathrm{CNC})$
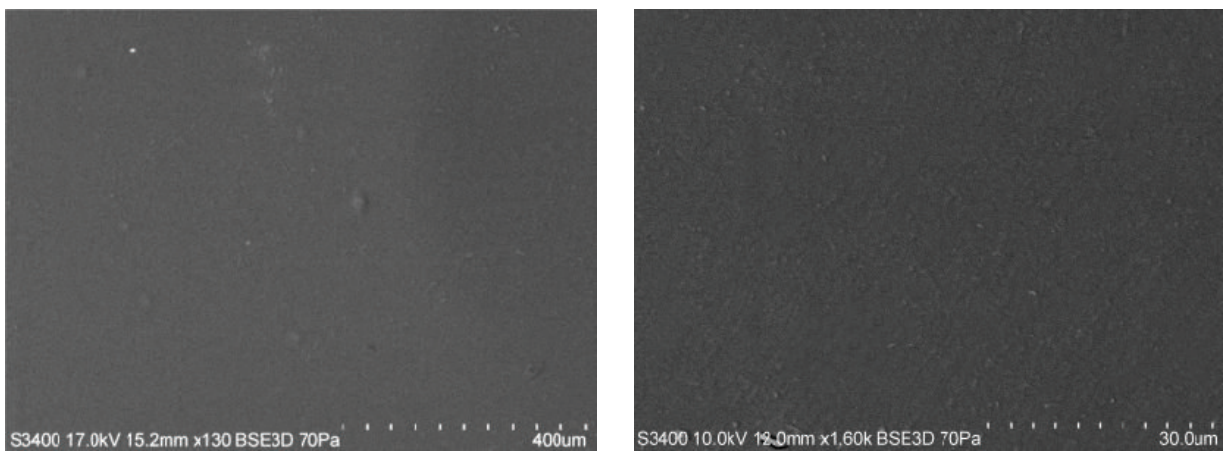

Coated PLA film $-8 *(\mathrm{CH}-\mathrm{CNC})$
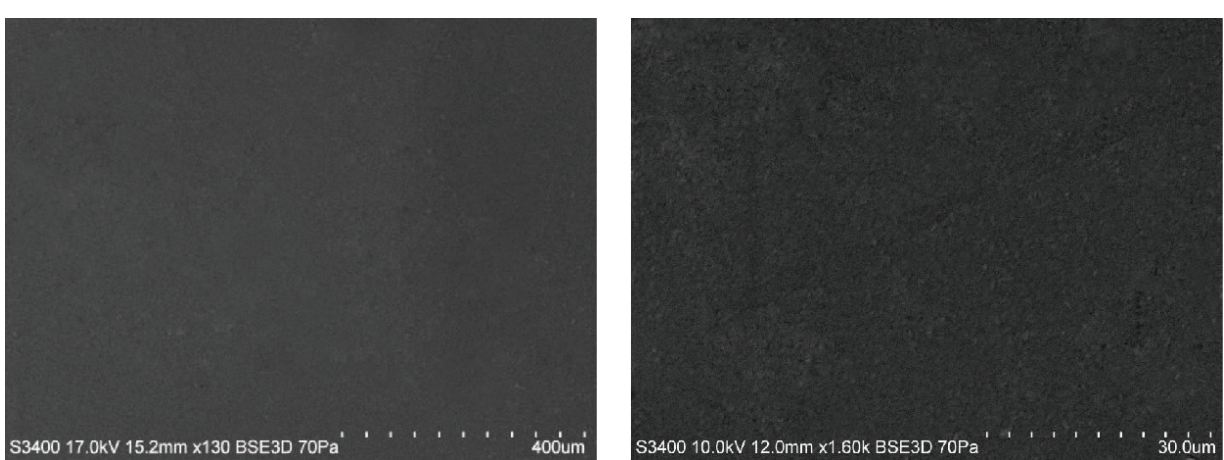

FIgURE 3: SEM images of the neat and coated PLA films.

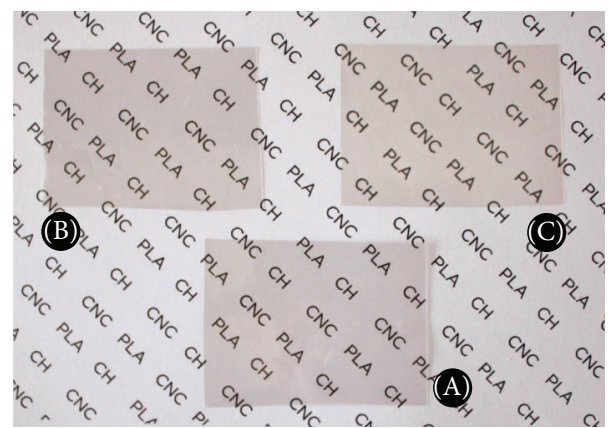

Figure 4: Neat (A) and coated PLA films ((B) $4 *(\mathrm{CH}-\mathrm{CNC})$ and (C) $8 *(\mathrm{CH}-\mathrm{CNC})$ ). well-adsorbed biocoating was carried out, which can improve the barrier properties of the PLA films and bottles up to 4 bilayers on each side. Due to the high water vapor transmission, PLA is mostly applied for short shelf-life products. In case of LbL-coated $4 *$ (CH-CNC) PLA films or bottles the shelf-life can be extended with almost $1 / 3$ times. The $\mathrm{CH}-$ CNC coating could be suitable for food packaging applications since chitosan is already applied in the food industry and cellulose nanomaterials are also proven to be noncytotoxic [19-21]. Furthermore $\mathrm{CH}$ and CNC suit the PLA as well because of the biodegradability and compostability of both materials.

Layer-by-layer electrostatic deposition can be an effective method in creating barrier coatings on PLA with choosing 


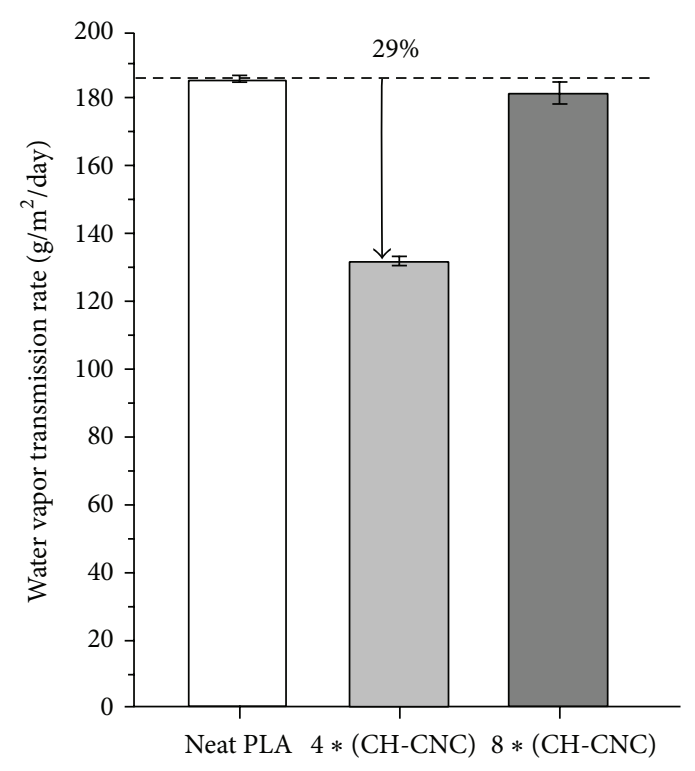

(a)

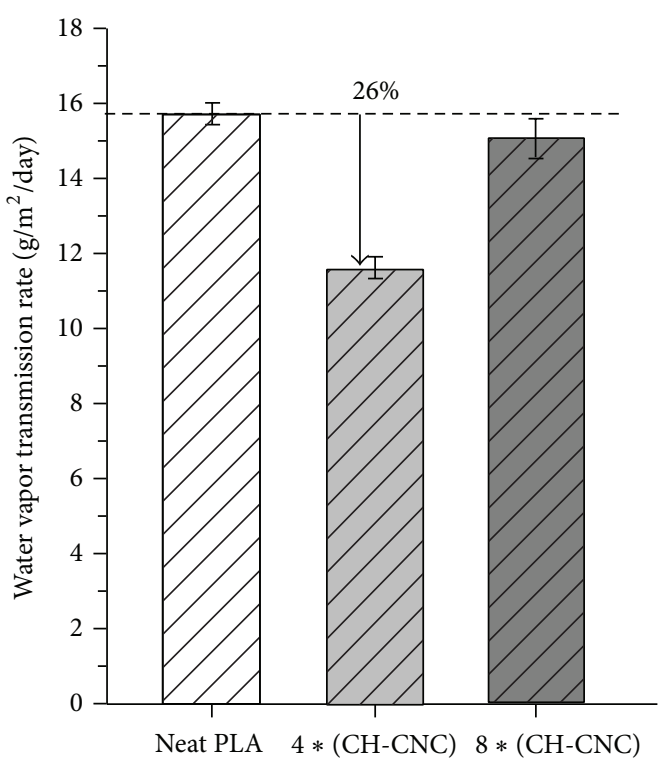

(b)

Figure 5: The water vapor transmission rate of neat and coated PLA films (a) and bottles (b).

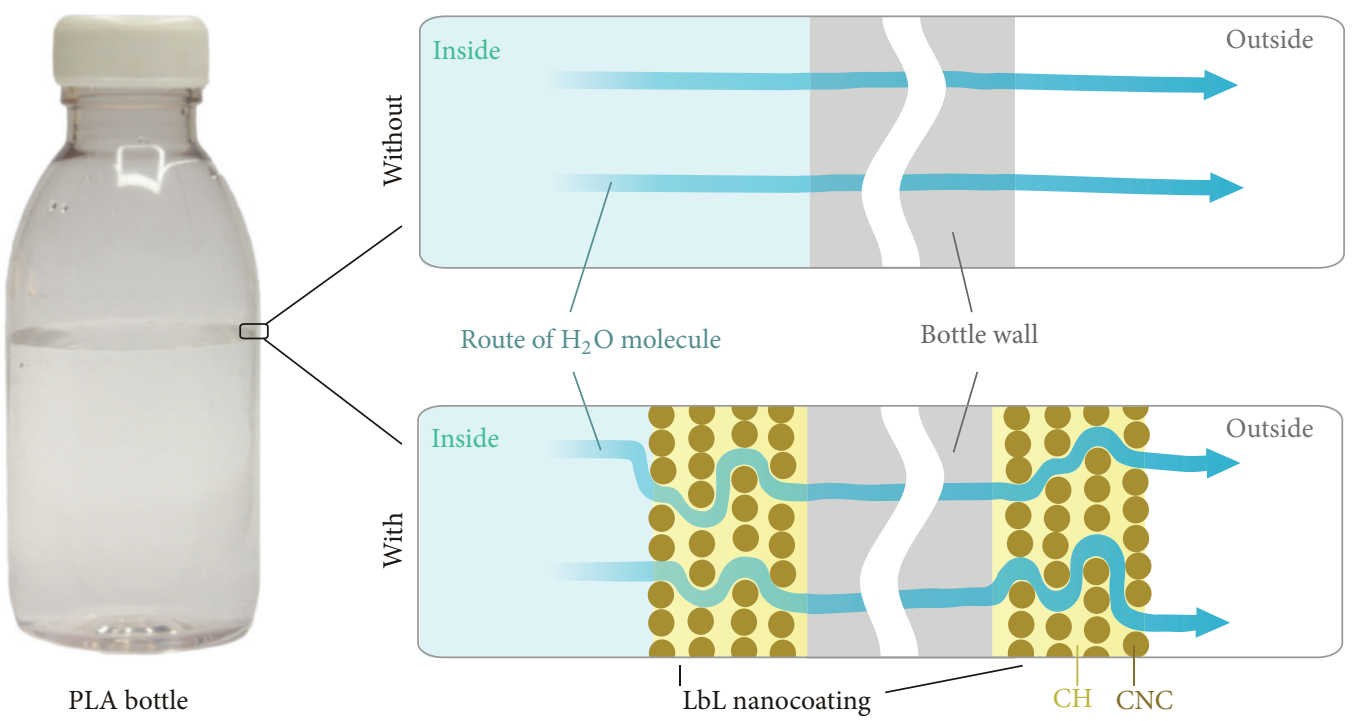

FIGURE 6: Schematic illustration of water vapor transmission rate reducing mechanism of $\mathrm{CH}$-CNC nanocoating.

the suitable components; furthermore besides barrier properties, other functionalities can be provided to the material with chitosan and cellulose nanocrystals like antimicrobility or wear resistance $[16,17,22-24]$. However, to validate the usability of such coatings, to prove that there is no migration of the constituents into the contained liquid, further investigation is required.

\section{Conflict of Interests}

The authors declare that there is no conflict of interests regarding the publication of this paper.

\section{References}

[1] W.-S. Jang, I. Rawson, and J. C. Grunlan, "Layer-by-layer assembly of thin film oxygen barrier," Thin Solid Films, vol. 516, no. 15, pp. 4819-4825, 2008.

[2] H. Ai, S. A. Jones, and Y. M. Lvov, "Biomedical applications of electrostatic layer-by-layer nano-assembly of polymers, enzymes, and nanoparticles," Cell Biochemistry and Biophysics, vol. 39, no. 1, pp. 23-43, 2003.

[3] B. Bolto and J. Gregory, "Organic polyelectrolytes in water treatment," Water Research, vol. 41, no. 11, pp. 2301-2324, 2007.

[4] M. M. de Villiers, D. P. Otto, S. J. Strydom, and Y. M. Lvov, "Introduction to nanocoatings produced by layer-by-layer 
(LbL) self-assembly," Advanced Drug Delivery Reviews, vol. 63, no. 9, pp. 701-715, 2011.

[5] P. R. van Tassel, "Polyelectrolyte adsorption and layer-by-layer assembly: electrochemical control," Current Opinion in Colloid and Interface Science, vol. 17, no. 2, pp. 106-113, 2012.

[6] G. Findenig, S. Leimgruber, R. Kargl, S. Spirk, K. StanaKleinschek, and V. Ribitsch, "Creating water vapor barrier coatings from hydrophilic components," ACS Applied Materials \& Interfaces, vol. 4, no. 6, pp. 3199-3206, 2012.

[7] M. A. Priolo, D. Gamboa, and J. C. Grunlan, "Transparent claypolymer nano brick wall assemblies with tailorable oxygen barrier," ACS Applied Materials \& Interfaces, vol. 2, no. 1, pp. 312-320, 2010.

[8] M. A. Priolo, K. M. Holder, D. Gamboa, and J. C. Grunlan, "Influence of clay concentration on the gas barrier of claypolymer nanobrick wall thin film assemblies," Langmuir, vol. 27, no. 19, pp. 12106-12114, 2011.

[9] A. J. Svagan, A. Akesson, M. Cardenas et al., "Transparent films based on PLA and montmorillonite with tunable oxygen barrier properties," Biomacromolecules, vol. 13, no. 2, pp. 397-405, 2012.

[10] G. Laufer, C. Kirkland, A. A. Cain, and J. C. Grunlan, "Claychitosan nanobrick walls: completely renewable gas barrier and flame-retardant nanocoatings," ACS Applied Materials \& Interfaces, vol. 4, no. 3, pp. 1643-1649, 2012.

[11] G. Laufer, C. Kirkland, A. A. Cain, and J. C. Grunlan, "Oxygen barrier of multilayer thin films comprised of polysaccharides and clay," Carbohydrate Polymers, vol. 95, no. 1, pp. 299-302, 2013.

[12] D. A. Hagen, B. Foster, B. Stevens, and J. C. Grunlan, "Shift-time polyelectrolyte multilayer assembly: fast film growth and high gas barrier with fewer layers by adjusting deposition time," ACS Macro Letters, vol. 3, no. 7, pp. 663-666, 2014.

[13] T. Hirvikorpi, M. Vähä-Nissi, A. Harlin et al., "Enhanced water vapor barrier properties for biopolymer films by polyelectrolyte multilayer and atomic layer deposited $\mathrm{Al}_{2} \mathrm{O}_{3}$ double-coating," Applied Surface Science, vol. 257, no. 22, pp. 9451-9454, 2011.

[14] L. Csóka, I. C. Hoeger, O. J. Rojas, I. Peszlen, J. J. Pawlak, and P. N. Peralta, "Piezoelectric effect of cellulose nanocrystals thin films," ACS Macro Letters, vol. 1, no. 7, pp. 867-870, 2012.

[15] K. Halász and L. Csóka, "Plasticized biodegradable poly(lactic acid) based composites containing cellulose in micro and nanosize," Journal of Engineering, vol. 2013, Article ID 329379, 9 pages, 2013.

[16] J. Fu, J. Ji, W. Yuan, and J. Shen, "Construction of anti-adhesive and antibacterial multilayer films via layer-by-layer assembly of heparin and chitosan," Biomaterials, vol. 26, no. 33, pp. 66846692, 2005.

[17] M. D. Sanchez-Garcia and J. M. Lagaron, "On the use of plant cellulose nanowhiskers to enhance the barrier properties of polylactic acid," Cellulose, vol. 17, no. 5, pp. 987-1004, 2010.

[18] K. Halász, Effect of montmorillointe nanoplatelets, cellulose micro- and nanocrystal on the properties of poly(lactic acid) matrix [Ph.D. dissertation], University of West Hungary, Sopron, Hungary, 2014.

[19] O. Rojas, J. Laine, and M. Österberg, "Nanocellulose-materials, functions and environmental aspects," in Proceedings of the OECD Conference on Potentieal Environmental Benefits of Nanotechnology: Fostering Safe Innovtion-Led Growth, Paris, France, July 2009.

[20] T. Kovacs, V. Naish, B. O'Connor et al., "An ecotoxicological characterization of nanocrystalline cellulose," Nanotoxicology, vol. 4, no. 3, pp. 255-270, 2010.
[21] K. Hua, D. O. Carlsson, E. Ålander et al., “Translational study between structure and biological response of nanocellulose from wood and green algae," RSC Advances, vol. 4, no. 6, pp. 2892-2903, 2014.

[22] A. P. Gomes, J. F. Mano, J. A. Queiroz, and I. C. Gouveia, "Layerby-layer deposition of antibacterial polyelectrolytes on cotton fibers," Journal of Polymers and the Environment, vol. 20, no. 4, pp. 1084-1094, 2012.

[23] I. Hoeger, O. J. Rojas, K. Efimenko, O. D. Velev, and S. S. Kelley, "Ultrathin film coatings of aligned cellulose nanocrystals from a convective-shear assembly system and their surface mechanical properties," Soft Matter, vol. 7, no. 5, pp. 1957-1967, 2011.

[24] M. Joshi, R. Khanna, R. Shekhar, and K. Jha, "Chitosan nanocoating on cotton textile substrate using layer-by-layer selfassembly technique," Journal of Applied Polymer Science, vol. 119, no. 5, pp. 2793-2799, 2011. 

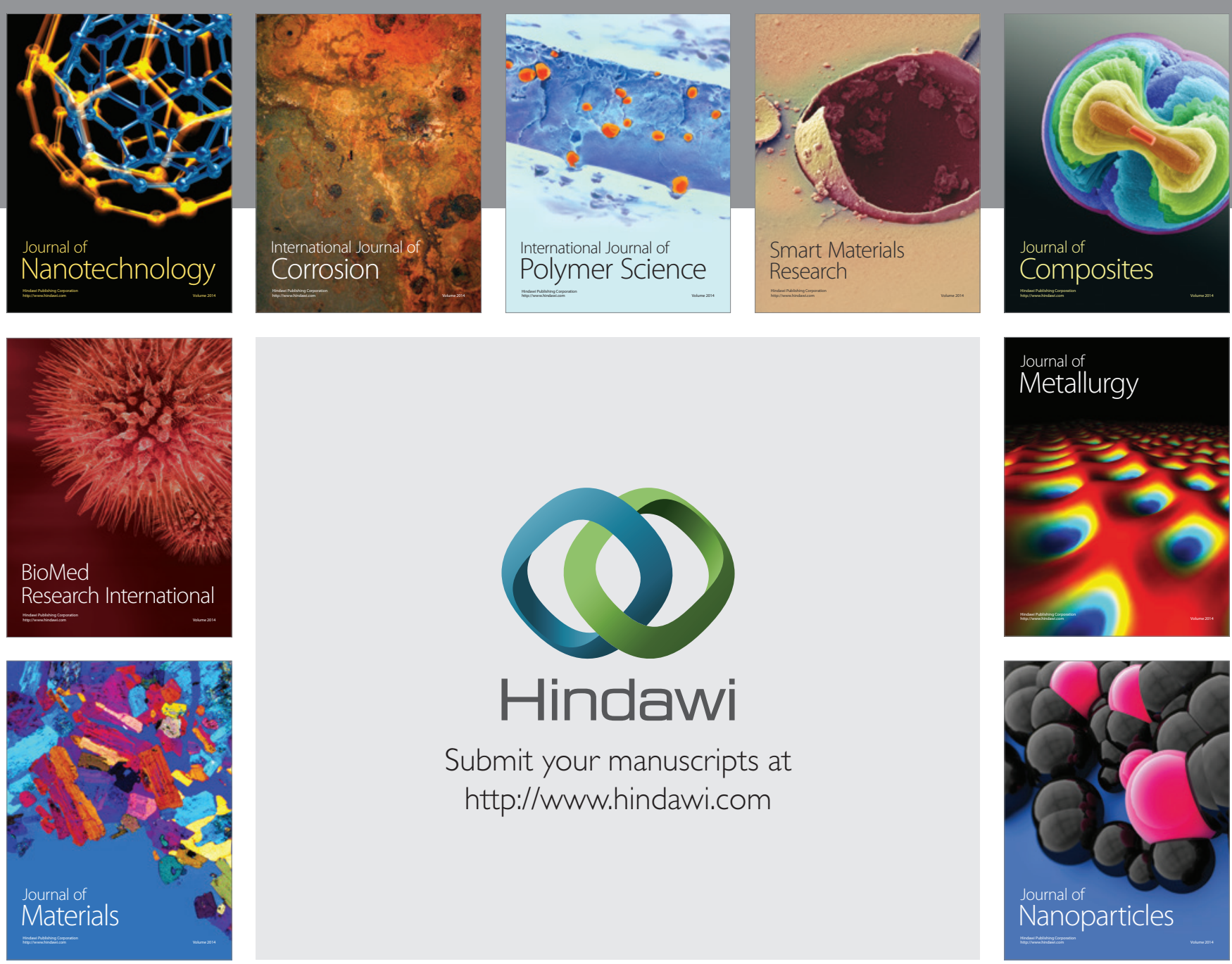

Submit your manuscripts at http://www.hindawi.com
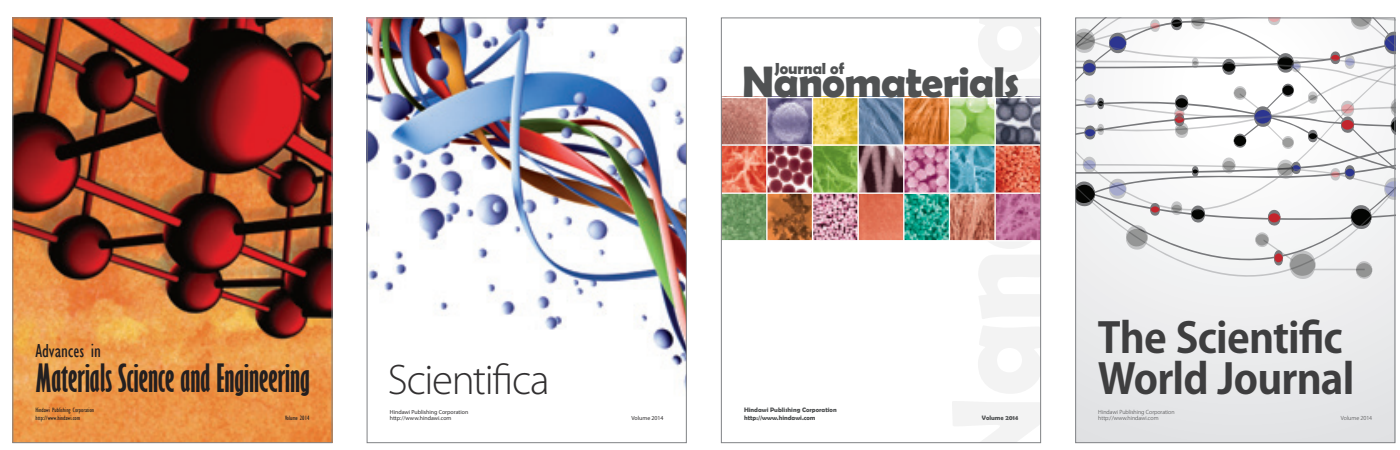

\section{The Scientific World Journal}
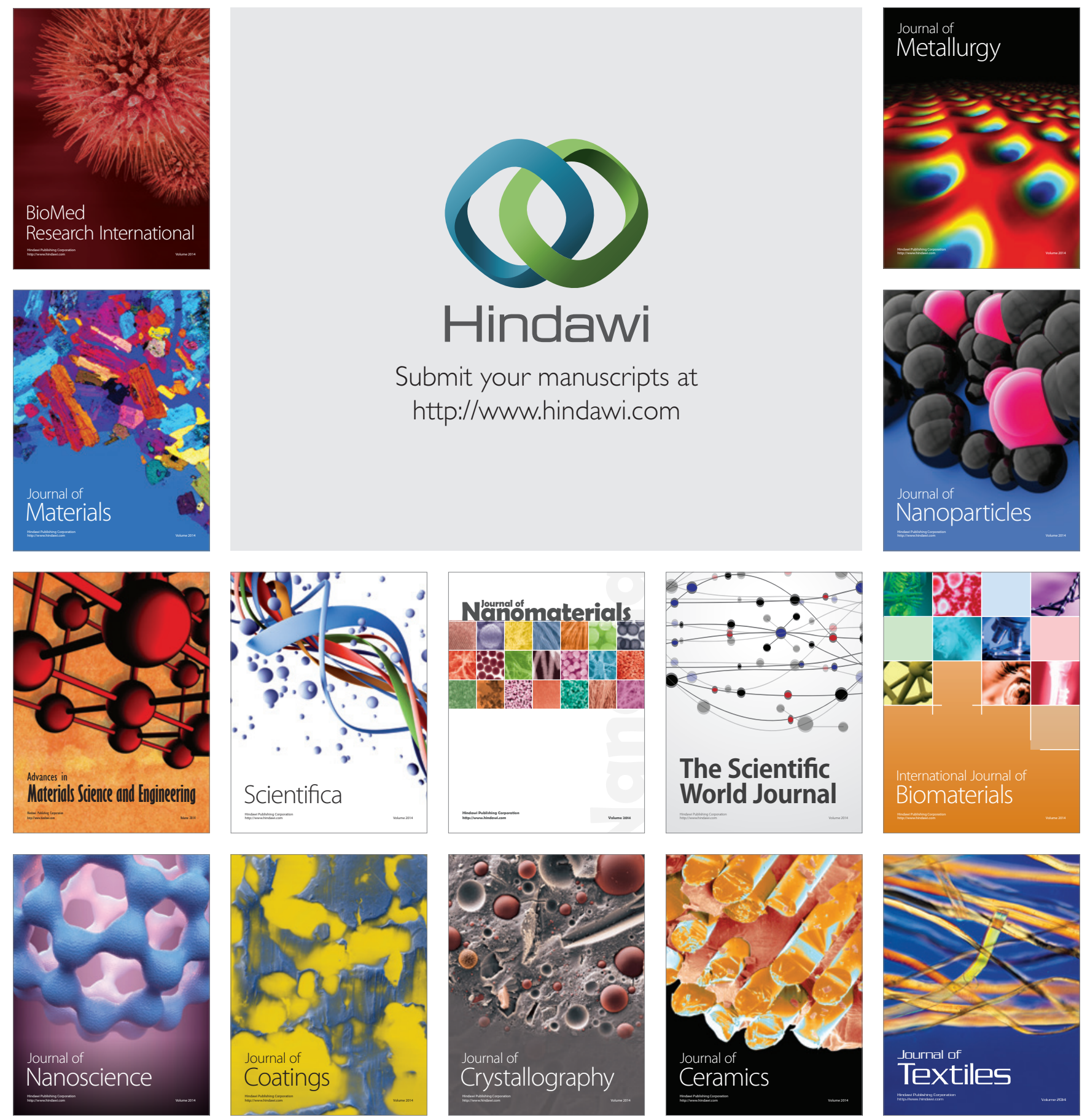